\title{
Optimization of p-GaN/InGaN/n-GaN Double Heterojunction p-i-n Solar Cell for High Efficiency: Simulation Approach
}

\author{
Aniruddha Singh Kushwaha, ${ }^{1,2,3}$ Pramila Mahala, ${ }^{4}$ and Chenna Dhanavantri ${ }^{2,3}$ \\ ${ }^{1}$ Indian Institute of Technology, Bombay (IIT-B) Powai, Maharashtra 400076, India \\ ${ }^{2}$ Academy of Scientific and Innovative Research, New Delhi 110001, India \\ ${ }^{3}$ Council of Scientific and Industrial Research-Central Electronics Engineering Research Institute (CSIR-CEERI) Pilani, \\ Rajasthan 333031, India \\ ${ }^{4}$ School of Solar Energy, Pandit Deendayal Petroleum University (PDPU), Gandhinagar, Gujarat 382007, India
}

Correspondence should be addressed to Pramila Mahala; pramila.mahala98@gmail.com

Received 29 May 2013; Accepted 13 March 2014; Published 10 April 2014

Academic Editor: Adel M. Sharaf

Copyright (C) 2014 Aniruddha Singh Kushwaha et al. This is an open access article distributed under the Creative Commons Attribution License, which permits unrestricted use, distribution, and reproduction in any medium, provided the original work is properly cited.

\begin{abstract}
We have conducted numerical simulation of $\mathrm{p}-\mathrm{GaN} / \mathrm{In}_{0.12} \mathrm{Ga}_{0.88} \mathrm{~N} / \mathrm{n}-\mathrm{GaN}$, p-i-n double heterojunction solar cell. The doping density, individual layer thickness, and contact pattern of the device are investigated under solar irradiance of AM1.5 for optimized performance of solar cell. The optimized solar cell characteristic parameters for cell area of $1 \times 1 \mathrm{~mm}^{2}$ are open circuit voltage of $2.26 \mathrm{~V}$, short circuit current density of $3.31 \mathrm{~mA} / \mathrm{cm}^{2}$, fill factor of $84.6 \%$, and efficiency of $6.43 \%$ with interdigitated grid pattern.
\end{abstract}

\section{Introduction}

The direct and tunable band gap of InGaN semiconductor offers a unique opportunity to develop high efficiency solar cell. The direct band gap of the InGaN semiconductor can vary from 0.7 to $3.4 \mathrm{eV}$ [1], which covers a broad solar spectrum from near-infrared to near-ultraviolet wavelength region. InGaN alloys show the unique properties such as tunable band gap, high carrier mobility, and high radiation resistance which offers a great advantage in design and fabrication of high efficiency devices for photovoltaic applications [2-4]. High absorption coefficient of InGaN alloys also makes it suitable to use in solar cells [5-7]. Earlier theoretical calculations have shown that it is possible to achieve efficiency up to $50 \%$ with InGaN alloys [8]. In spite of high efficiency prediction, fabricated solar cells could not demonstrate high efficiency [9-13]. The epitaxial growth of InGaN layers faces many issues such as lack of defect-free substrate, indium segregation at higher composition, and large lattice mismatch between $\mathrm{InN}$ and $\mathrm{GaN}$ which leads to phase separation [14]. In addition, there are significant polarization charges at the InGaN/GaN interface which alter the electric field in InGaN layer [15]. As a consequence the fabricated InGaN solar cell shows very low conversion efficiency compared to theoretical calculation.

In this paper, a simulation work is carried out to optimize p-GaN/InGaN/n-GaN/sapphire device structure of solar cells with $12 \%$ indium composition under AM1.5 illumination. Simulation is carried out by optimizing doping concentration and thickness of p-GaN, InGaN, and n-GaN layer, respectively, by changing only one material parameter at a time and keeping other parameters constant. Simulation verifies that device efficiency is strongly dependent on the intrinsic-layer (InGaN) thickness, as most of the spectrum is absorbed in this layer. We simulate $\mathrm{p}-\mathrm{GaN} / \mathrm{InGaN} / \mathrm{n}$ GaN/Sapphire solar cell to investigate the effect of incorporating grid contact pattern on the device characteristic parameter. It is observed that optimization of grid contact spacing helps greatly in device efficiency enhancement.

TCAD SILVACO, Version: ATLAS 5.16.3.R, is used for simulation. The simulator works on mathematical models which consist of fundamental equations such as Poisson's equation, continuity equation, and transport equations. In our simulation, we have used the models such as AUGER for 
TABLE 1: Material parameter used in simulation.

\begin{tabular}{|c|c|c|c|}
\hline Parameter & $\mathrm{GaN}$ & $\mathrm{In}_{0.12} \mathrm{Ga}_{0.88} \mathrm{~N}$ & $\operatorname{InN}$ \\
\hline Band gap $E_{g}(\mathrm{ev})[10]$ & 3.42 & 2.93 & 0.7 \\
\hline Lattice constant $\left(\mathrm{A}^{\circ}\right)[11]$ & 3.18 & 3.23 & 3.6 \\
\hline Minority carrier life time (ns) [21] & 1 & 1 & 1 \\
\hline Spontaneous polarization (sheet charge per $\mathrm{cm}^{2}$ ) [22] & $-2.12 e 13$ & $-2.18 e 13$ & $-2.63 e 13$ \\
\hline Piezoelectric polarization (sheet charge per $\mathrm{cm}^{2}$ ) [22] & 0 & $-8.87 e 12$ & $9.98 e 13$ \\
\hline Auger coefficient n-type [11] & $1 e-34$ & $1 e-34$ & $1 e-34$ \\
\hline Auger coefficient p-type [11] & $1 e-34$ & $1 e-34$ & $1 e-34$ \\
\hline
\end{tabular}

Auger recombination, SRH for Shockley Read Hall recombination, OPTR for optical recombination, KP model for effective masses, and band edge energies for drift diffusion simulation. Mathematical models are used in simulation which consists of fundamental equations such as Poisson's equation, continuity equation, and transport equations. Newton's method is used as the solution method in simulation. All the above models are used from standard TCAD library.

This paper is organized as follows: in Section 2 material parameters are described which are used in simulation models. Section 3 discusses simulation and results. Finally, conclusion is presented in Section 4.

\section{Material Parameters}

The absorption coefficient $\alpha(E)$ of $\operatorname{In}_{x} \mathrm{Ga}_{1-x} \mathrm{~N}$ semiconductor as a function of energy [16], energy band gap and electron affinity as a function of band gap energy, $E_{g}(x)[17,18]$, and electron and hole mobility as a function of doping [19] can be expressed as

$$
\begin{gathered}
\alpha[E(\lambda)]=\alpha_{0} \sqrt{\frac{E(\lambda)-E_{g}(x)}{E_{g}(x)}}, \\
E_{g}(x)=0.7 x+3.4(1-x)-1.43 x(1-x) \mathrm{eV}, \\
\chi=4.1+0.7 \times\left(3.4-E_{g}(x)\right), \\
\mu_{i}(N)=\mu_{\min , i}+\frac{\mu_{\max , i}-\mu_{\min , i}}{1+\left(N / N_{g, i}\right)^{\gamma_{i}}},
\end{gathered}
$$

where $E(\lambda)$ is the energy of photon corresponding to respective wavelength and $E_{g}(x)$ is the band gap of $\operatorname{In}_{x} \mathrm{Ga}_{1-x} \mathrm{~N}$ semiconductor. It is assumed that $\alpha_{0}$ for $\operatorname{In}_{x} \mathrm{Ga}_{1-x} \mathrm{~N}$ is the same as that of GaN, $i$ denotes electrons (e) or holes (h), $N$ is doping concentration, and $\mu_{\min }, \mu_{\max }, \gamma$, and $N_{g}$ are the parameter given for a specific semiconductor [19]. The material parameters for InGaN such as absorption coefficient, lattice constant, and polarization charges are derived and extracted by interpolation of known material parameters of InN and GaN. Some of important material parameters used during simulation are listed in Table 1.

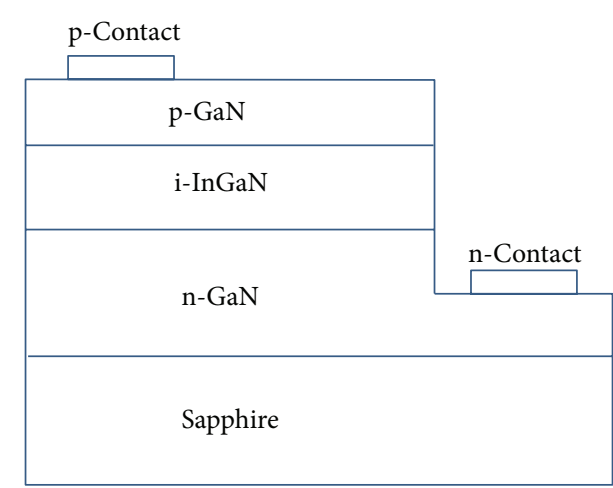

FIGURE 1: p-i-n InGaN/GaN double heterojunction solar cell structure.

\section{Simulation Results and Discussion}

3.1. Optimization of $p-i-n$ Structure. The schematic diagram of InGaN/GaN p-i-n solar cell is shown in Figure 1. The p$\mathrm{GaN}$ layer thickness is varied from 70 to $120 \mathrm{~nm}$. The InGaN and n-GaN layer thicknesses $100 \mathrm{~nm}$ and $1.5 \mu \mathrm{m}$ and their doping densities $1 \times 10^{16} \mathrm{~cm}^{-3}$ and $6 \times 10^{18} \mathrm{~cm}^{-3}$, respectively, are kept constant while optimizing $\mathrm{p}-\mathrm{GaN}$ layer thickness and doping density.

The effect of $\mathrm{p}-\mathrm{GaN}$ layer thickness and doping concentration on solar cells characteristic parameters such as short circuit current density, open circuit voltage, fill factor, and efficiency is shown in Figure 2. The short circuit current density, $J_{\mathrm{sc}}$, increases with $\mathrm{p}$-GaN layer thickness. As the thickness of $\mathrm{p}-\mathrm{GaN}$ layer increases more photon absorption occurs in the p-region, resulting in more electron and hole carrier generation that contributes to enhancement of current density. On the contrary, thicker p-GaN layer increases surface recombination rate after a certain thickness; current density starts decreasing. The open circuit voltage, $V_{\text {oc }}$, and fill factor, FF, do not show significant change with respect to $\mathrm{p}-\mathrm{GaN}$ layer thickness as these parameters largely depend on the bulk property of semiconductor rather than surface property.

The effect of doping density is analyzed by simulating the structure for different doping concentrations of $1 \times$ $10^{16} \mathrm{~cm}^{-3}, 1 \times 10^{17} \mathrm{~cm}^{-3}$, and $1 \times 10^{18} \mathrm{~cm}^{-3}$, respectively. The simulation result shows that the short circuit current density is higher for doping concentration of $1 \times 10^{16} \mathrm{~cm}^{-3}$. However, 


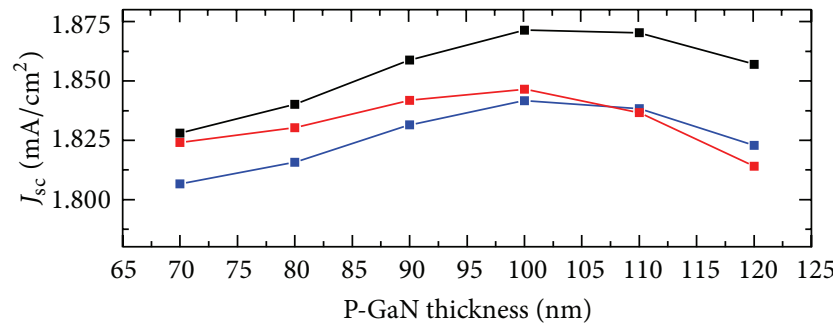

(a)

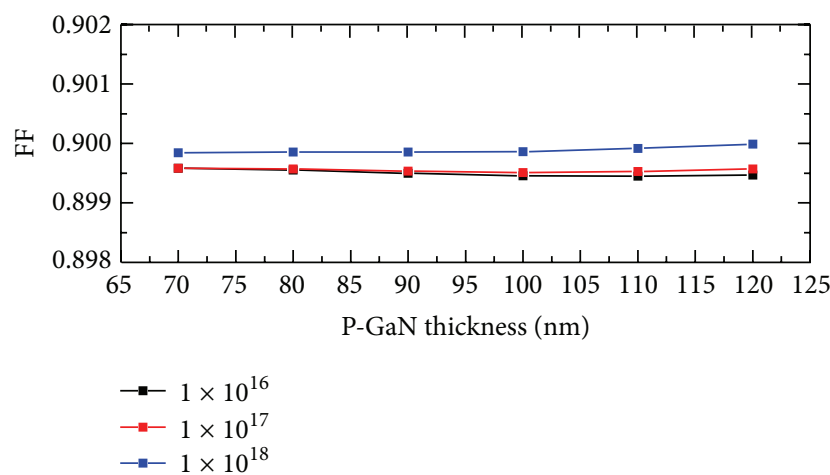

(c)

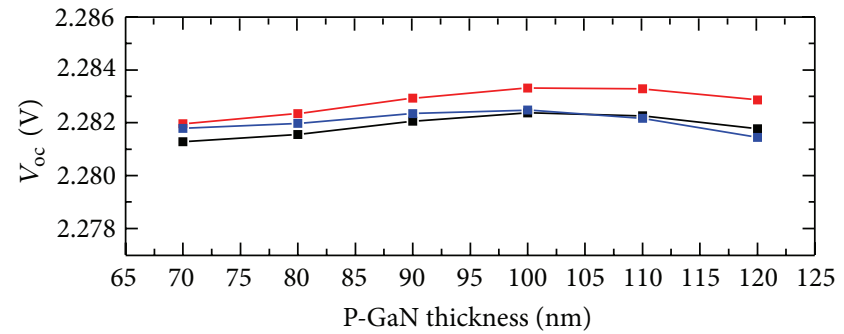

(b)

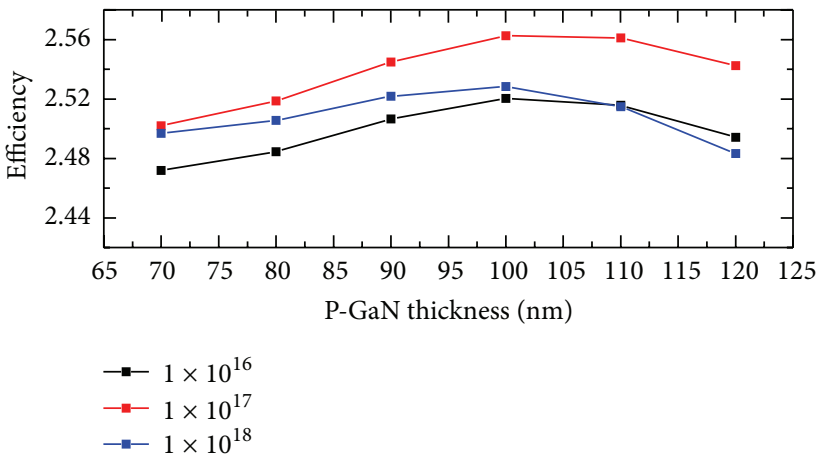

(d)

FIGURE 2: Effect of p-GaN layer thickness and doping concentrations on GaN/InGaN solar cell characteristic parameters: (a) short circuit current density, (b) open circuit voltage, (c) fill factor, and (d) efficiency.

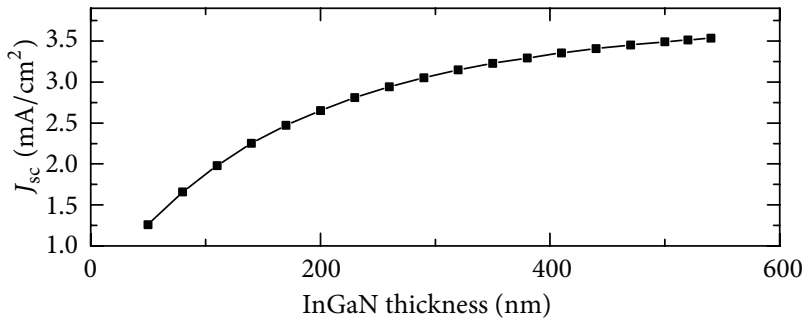

(a)

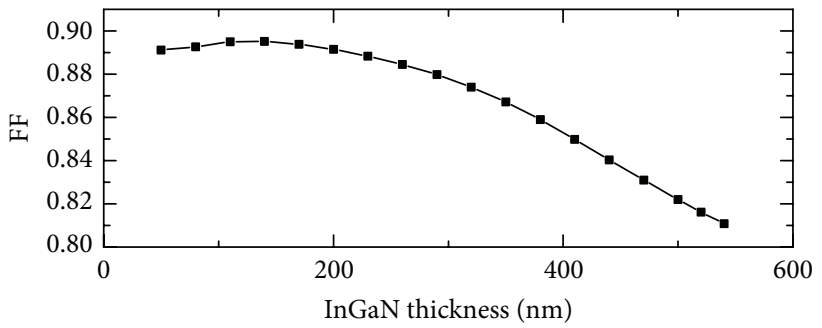

(c)

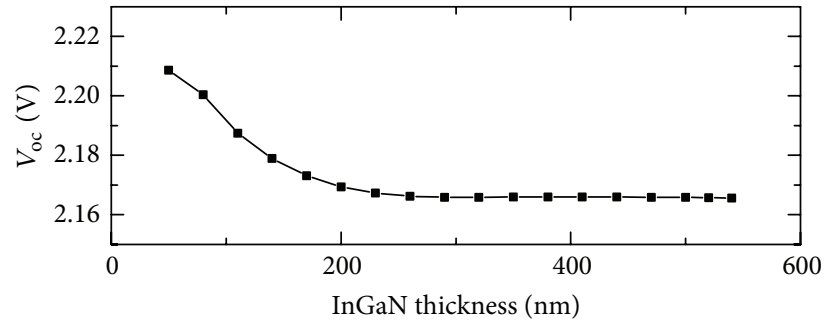

(b)

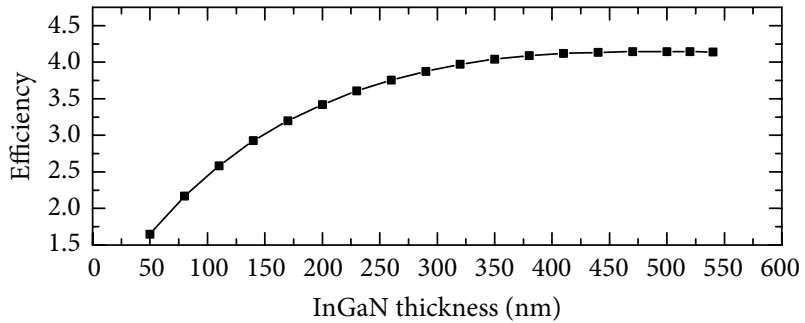

(d)

FiguRE 3: Effect of InGaN layer thickness on characteristic parameters of solar cells. (a) Short circuit current density. (b) Open circuit voltage. (c) Fill factor. (d) Efficiency.

it is found that $V_{\mathrm{oc}}$ is higher for doping concentration of $1 \times$ $10^{17} \mathrm{~cm}^{-3}$. The combined effect of $J_{\text {sc }}$ and $V_{\text {oc }}$ determines the efficiency curve which follows curve pattern of $J_{\text {sc }}$ and shows higher efficiency for the doping concentration of $1 \times$ $10^{17} \mathrm{~cm}^{-3}$, where $V_{\text {oc }}$ is high.
The effect of intrinsic InGaN layer thickness on solar cell characteristic parameters of p-GaN/InGaN/n-GaN p-i$\mathrm{n}$ solar cell is shown in Figure 3. The InGaN layer thickness is varied from 50 to $550 \mathrm{~nm}$. The $\mathrm{p}-\mathrm{GaN}$ and $\mathrm{n}-\mathrm{GaN}$ layer thicknesses $100 \mathrm{~nm}$ and $1.5 \mu \mathrm{m}$ and their doping densities 5 


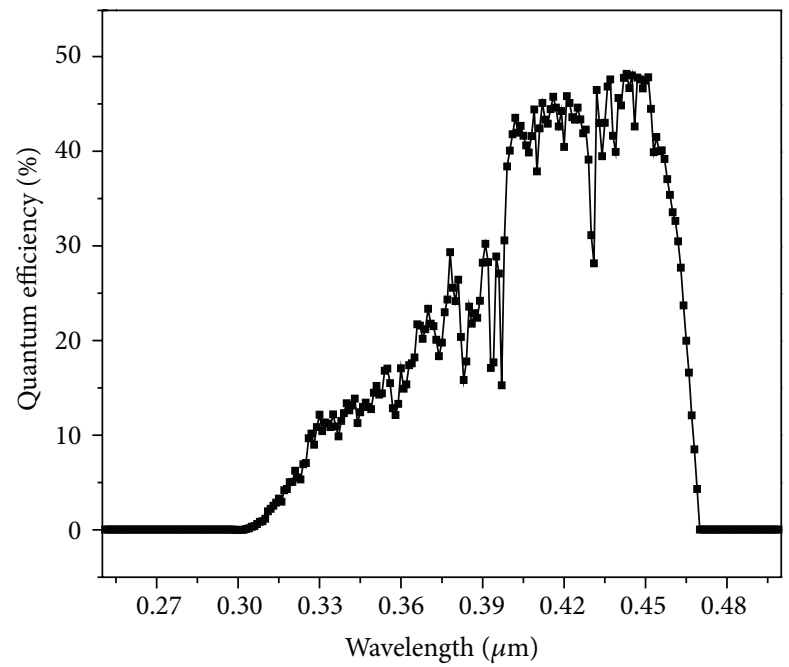

FIGURE 4: Quantum efficiency of optimized p-i-n GaN/InGaN double heterojunction solar cell.

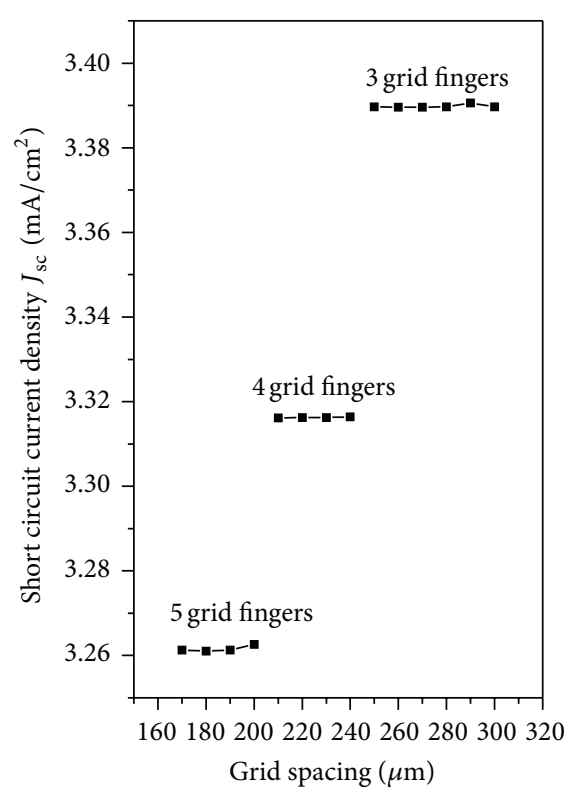

(a)

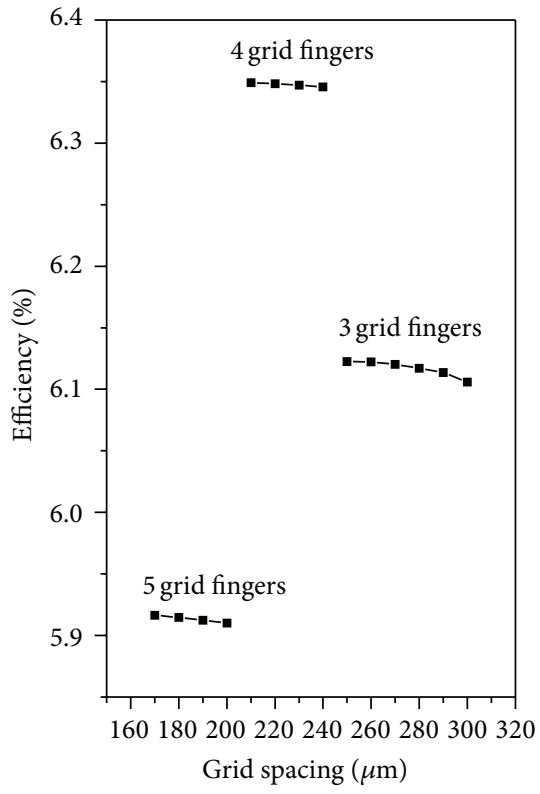

(b)

p-Contact

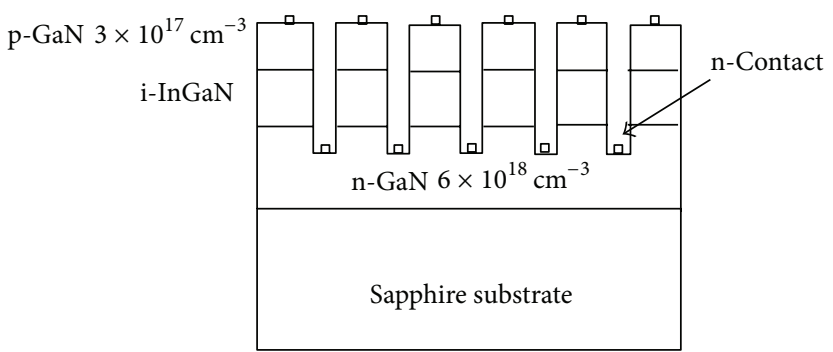

(c)

FIGURE 5: Effect of (a) short circuit current density, (b) efficiency on grid spacing for different number of grids, and (c) p-i-n InGaN/GaN double heterojunction solar cell with grid type contact. 
TABLE 2: Characteristic parameters of simulated InGaN p-i-n solar cell.

\begin{tabular}{|c|c|c|c|c|c|c|c|}
\hline Contact type & Effective device area $\left(\mathrm{mm}^{2}\right)$ & Grid spacing $(\mu \mathrm{m})$ & Indium (\%) & $J_{\mathrm{sc}}\left(\mathrm{mA} / \mathrm{cm}^{2}\right)$ & $V_{\mathrm{oc}}(\mathrm{V})$ & $\mathrm{FF}(\%)$ & $\eta(\%)$ \\
\hline Square pad & 0.96 & - & 12 & 5.64 & 2.27 & 82 & 4.16 \\
\hline \multicolumn{8}{|l|}{ Grid pattern } \\
\hline 5 grid fingers & 0.90 & 180 & 12 & 3.26 & 2.17 & 83.6 & 5.92 \\
\hline 4 grid fingers & 0.92 & 210 & 12 & 3.31 & 2.26 & 84.6 & 6.34 \\
\hline 3 grid fingers & 0.94 & 260 & 12 & 3.39 & 2.17 & 83.2 & 6.12 \\
\hline
\end{tabular}

$\times 10^{17} \mathrm{~cm}^{-3}$ and $6 \times 10^{18} \mathrm{~cm}^{-3}$, respectively, are kept constant while optimizing InGaN layer thickness.

It is found that $J_{\mathrm{sc}}$ increases with InGaN layer thickness since photons get longer path for absorption and also unabsorbed lower energy photons from p-GaN layer get absorbed in this region. Photon absorption is also supported by higher absorption coefficient of InGaN material [20]. On the other hand, the open circuit voltage is found to be decreased and remain nearly constant after layer thickness of $250 \mathrm{~nm}$. Higher thickness generates more carriers and recombination results in decreased open circuit voltage.

The fill factor also starts decreasing with respect to increased InGaN layer thickness. The series resistance increases with increasing InGaN layer thickness. The efficiency curve resembles that of current density which represents the combined effect of all parameters $S_{C}, V_{\mathrm{ic}}$, and FF. After the p-GaN and InGaN-layers, the $n-G a N$ layer thickness and doping density concentration are optimized. The $n-G a N$ thickness is varied from 0.4 to $2.4 \mu \mathrm{m}$. The $\mathrm{p}-\mathrm{GaN}$ and InGaN layers thicknesses are $100 \mathrm{~nm}$ and $450 \mathrm{~nm}$ and doping densities $5 \times 10^{17} \mathrm{~cm}^{-3}$ and $1 \times 10^{16} \mathrm{~cm}^{-3}$, respectively, are kept constant while optimizing $\mathrm{n}-\mathrm{GaN}$ layer thickness and doping density. The n-GaN layer thickness and doping density do not play an important role with respect to solar cell parameters. It may be because most of the available photons are already absorbed in the $\mathrm{p}-\mathrm{GaN}$ and $\mathrm{InGaN}$ layer, and very few carriers are generated in $\mathrm{n}-\mathrm{GaN}$ layer.

The final p-i-n structure consists of n-type GaN layer, $1.5 \mu \mathrm{m}$ thickness and doping density of $6 \times 10^{18} \mathrm{~cm}^{-3}$, unintentionally doped InGaN layer, $450 \mathrm{~nm}$ thickness and doping density of $1 \times 10^{16} \mathrm{~cm}^{-3}$ with 12 percent indium composition, and top p-type GaN layer, $100 \mathrm{~nm}$ thickness, with acceptor density of $5 \times 10^{17} \mathrm{~cm}^{-3}$. The quantum efficiency of optimized structure is calculated and shown in Figure 4 and the maximum quantum efficiency is found to be in the wavelength range of $0.4 \mathrm{~nm}$ to $0.45 \mathrm{~nm}$ wavelength, which corresponds to $\mathrm{GaN} / \mathrm{InGaN}$ material band gap region.

3.2. Effect of using Interdigitated Grid Pattern. We simulated the $\mathrm{p}-\mathrm{i}-\mathrm{n}$ structure with interdigitated grid pattern, in order to further enhance the efficiency by use of grid type contact which helps in increasing the carrier collection. Simulation results of incorporating grid patterns on $x$ and efficiency with different numbers of grid fingers such as 3,4 , and 5 and different grid spacing from 175 to $375 \mu \mathrm{m}$ are shown in Figure 5. The size of the cell considered here is $1 \times$ $1 \mathrm{~mm}^{2}$. The number of grids will be reduced with increasing finger-to-finger grid spacing. The short circuit current density decreases with increasing grid numbers due to decrease in effective area available for photon absorption. However there is an enhancement in efficiency due to more carrier collection. The characteristic parameters for different contact patterns along with square pad are compared in Table 2.

\section{Conclusion}

The optimization of $\mathrm{p}-\mathrm{GaN} / \mathrm{InGaN} / \mathrm{n}-\mathrm{GaN}$ double heterojunction p-i-n solar cell with square contact and grid pattern is studied. The photovoltaic parameter of solar cell strongly depends on $\mathrm{p}-\mathrm{GaN}$ and InGaN layers thickness and doping density. Photovoltaic parameters, such as $V_{\mathrm{oc}}: 2.27 \mathrm{~V}, J_{\mathrm{sc}}$ : $5.64 \mathrm{~mA} / \mathrm{cm}^{2}$, FF: $82 \%$, and $\eta: 4.16$, are obtained for square contact type under 1 sun AM1.5 illumination with optimized p-GaN (100 nm, 5el7 am-3) and InGaN (In $=0.12,450 \mathrm{~nm})$ layers and high quantum efficiency of $\sim 50 \%$ is also achieved in wavelength range of $0.4 \mathrm{~nm}$ to $0.45 \mathrm{~nm}$ which corresponds to $\mathrm{In}_{0.12} \mathrm{Ga}_{0.88} \mathrm{~N}$ absorption region. In addition to optimizing structure, use of grid contact pattern with finger spacing of $210 \mathrm{~nm}$ improves conversion efficiency to 6.34 .

\section{Conflict of Interests}

The authors declare that there is no conflict of interests regarding the publication of this paper.

\section{Acknowledgments}

The authors gratefully acknowledge the Director of CSIRCEERI, Pilani, for his encouragement in this work. They also thank all ODG members for their help and cooperation.

\section{References}

[1] J. Wu, W. Walukiewicz, K. M. Yu et al., "Small band gap bowing in $\mathrm{In}_{1-x} \mathrm{Ga}_{x} \mathrm{~N}$ alloys," Applied Physics Letters, vol. 80, no. 25, pp. 4741-4743, 2002.

[2] X. M. Cai, S. W. Zeng, and B. P. Zhang, "Fabrication and characterization of InGaN p-i-n homojunction solar cell," Applied Physics Letters, vol. 95, Article ID 173504, 2009.

[3] Y. Nanishi, Y. Saito, and T. Yamaguchi, "RF-molecular beam epitaxy growth and properties of InN and related alloys," Journal of Applied Physics, vol. 42, part 1, pp. 2549-2559, 2003.

[4] X. Zheng, R. H. Horng, D. S. Wuu et al., "High-quality InGaN/GaN heterojunctions and their photovoltaic effects," Applied Physics Letters, vol. 93, Article ID 261108, 2008. 
[5] C. J. Neufeld, N. G. Toledo, S. C. Cruz et al., "High quantum efficiency InGaN/GaN solar cells with $2.95 \mathrm{eV}$ band gap," Applied Physics Letters, vol. 93, Article ID 143502, 2008.

[6] R. Singh, D. Doppalapudi, T. D. Moustakas, and L. T. Romano, "Phase separation in InGaN thick films and formation of In GaN/GaN double heterostructures in the entire alloy composition," Applied Physics Letters, vol. 70, no. 9, pp. 1089-1091, 1997.

[7] J. F. Muth, J. H. Lee, I. K. Shmagin et al., "Absorption coefficient, energy gap, exciton binding energy, and recombination lifetime of GaN obtained from transmission measurements," Applied Physics Letters, vol. 71, no. 18, pp. 2572-2574, 1997.

[8] A. De Vos, Endoreversible Thermodynamics of Solar Energy Conversion, Oxford University Press, Oxford, UK, 1992.

[9] X. Zhang, X. L. Wang, H. L. Xiao et al., "Simulation of $\mathrm{In}_{0.65} \mathrm{Ga}_{0.35} \mathrm{~N}$ single-junction solar cell," Journal of Physics $D$ : Applied Physics, vol. 40, no. 23, p. 7335, 2007.

[10] H. Hamzaoui, A. S. Bouazzi, and B. Rezig, "Theoretical possibilities of $\operatorname{In}_{x} \mathrm{Ga}_{1-x} \mathrm{~N}$ tandem PV structures," Solar Energy Materials and Solar Cells, vol. 87, no. 1-4, pp. 595-603, 2005.

[11] Md. R. Islam, A. N. M. E. Kabir, and A. G. Bhuiyan, "Projected Performance of $\operatorname{In}_{x} \mathrm{Ga}_{1-x} \mathrm{~N}$-based multi-junction solar cells," Istanbul University-Journal of Electrical and Electronics Engineering, vol. 6, no. 2, pp. 251-255, 2006.

[12] L. Hsu and W. Walukiewicz, "Modeling of InGaN/Si tandem solar cells," Journal of Applied Physics, vol. 104, Article ID 024507, 2008.

[13] B. W. Liou, " $\operatorname{In}_{x} \mathrm{Ga}_{1-x} \mathrm{~N}-\mathrm{GaN}$-based solar cells with a multiplequantum-well structure on $\mathrm{SiCN}-\mathrm{Si}(111)$ substrates," IEEE Photonics Technology Letters, vol. 22, no. 4, 2010.

[14] Y.-S. Lin, K.-J. Ma, C. Hsu et al., "Dependence of composition fluctuation on indium content in InGaN/GaN multiple quantum wells," Applied Physics Letters, vol. 77, no. 19, pp. 2988-2990, 2000.

[15] J. Wierer, A. Fischer, and D. Koleske, "The impact of piezoelectric polarization and nonradiative recombination on the performance of (0001) face GaN/InGaN photovoltaic devices," Applied Physics Letters, vol. 96, Article ID 051107, 2010.

[16] J. Hubin and A. V. Shah, "Effect of the recombination function on the collection in a p-i-n solar cell," Philosophical Magazine B, vol. 72, no. 6, pp. 589-599, 1995.

[17] M. E. Levinshtein, S. L. Rumyantsev, and M. S. Shur, Properties of Advanced Semiconductor Materials, Wiley, Chichester, UK, 2001.

[18] N. Li, Simulation and analysis of GaN-based photoelectronics devices [Ph.D. dissertation], Institute of Semiconductors, Chinese Academy of Sciences, Beijing, China, 2005, (Chinese).

[19] T. T. Mnatsakanov, M. E. Levinshtein, L. I. Pomortseva, S. N. Yurkov, G. S. Simin, and M. A. Khan, "Carrier mobility model for GaN,” Solid-State Electronics, vol. 47, no. 1, pp. 111-115, 2003.

[20] K. Kumakura, T. Makimoto, N. Kobayashi, T. Hashizume, T. Fukui, and H. Hasegawa, "Minority carrier diffusion length in GaN: dislocation density and doping concentration dependence," Applied Physics Letters, vol. 86, Article ID 052105, 2005.

[21] G. F. Brown, J. W. Ager III, W. Walukiewicz, and J. Wu, "Finite element simulations of compositionally graded InGaN solar cells," Solar Energy Materials and Solar Cells, vol. 94, no. 3, pp. 478-483, 2010.

[22] ATLAS User's Manual: Device Simulation Software, 06/11/08 Ed., Silvaco Data Systems, Inc., Santa Clara, Calif, USA, 2008. 

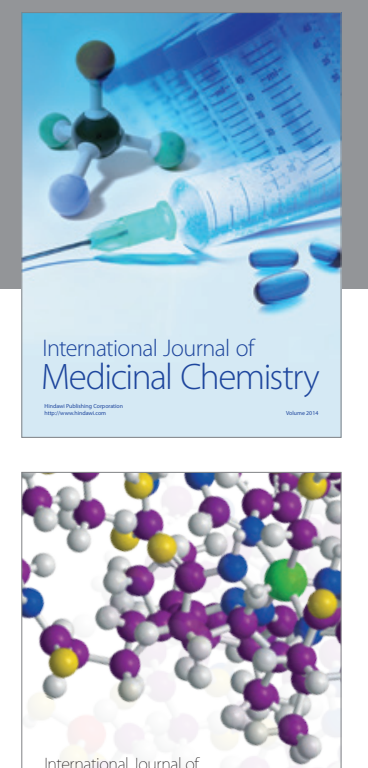

\section{Carbohydrate} Chemistry

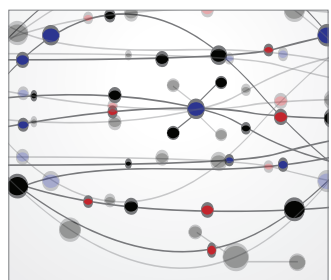

The Scientific World Journal
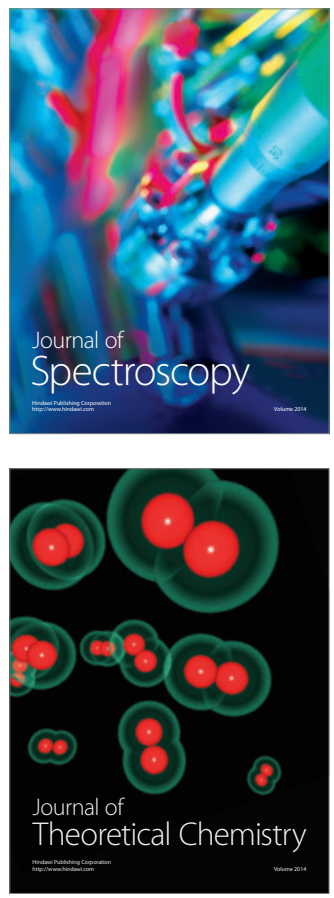
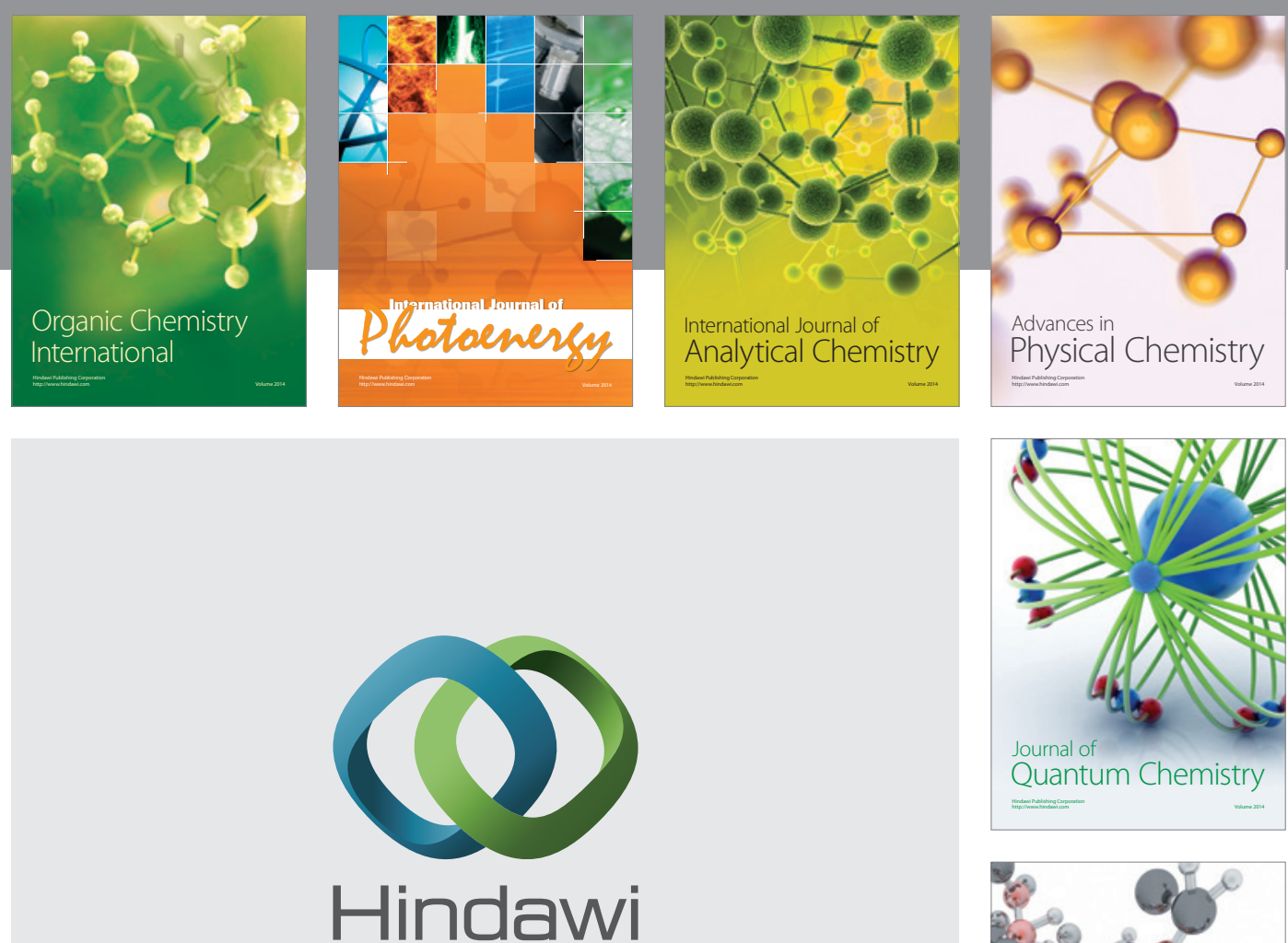

Submit your manuscripts at

http://www.hindawi.com

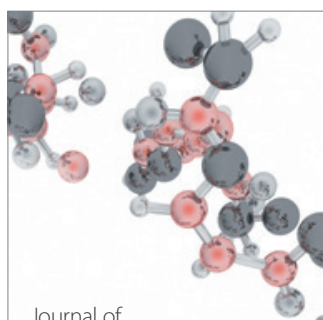

Analytical Methods

in Chemistry

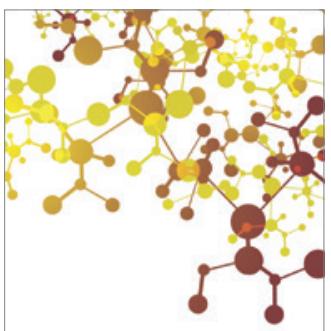

Journal of

Applied Chemistry

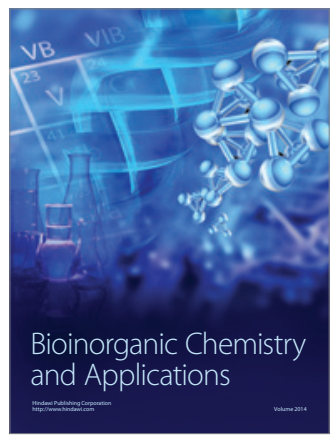

Inorganic Chemistry
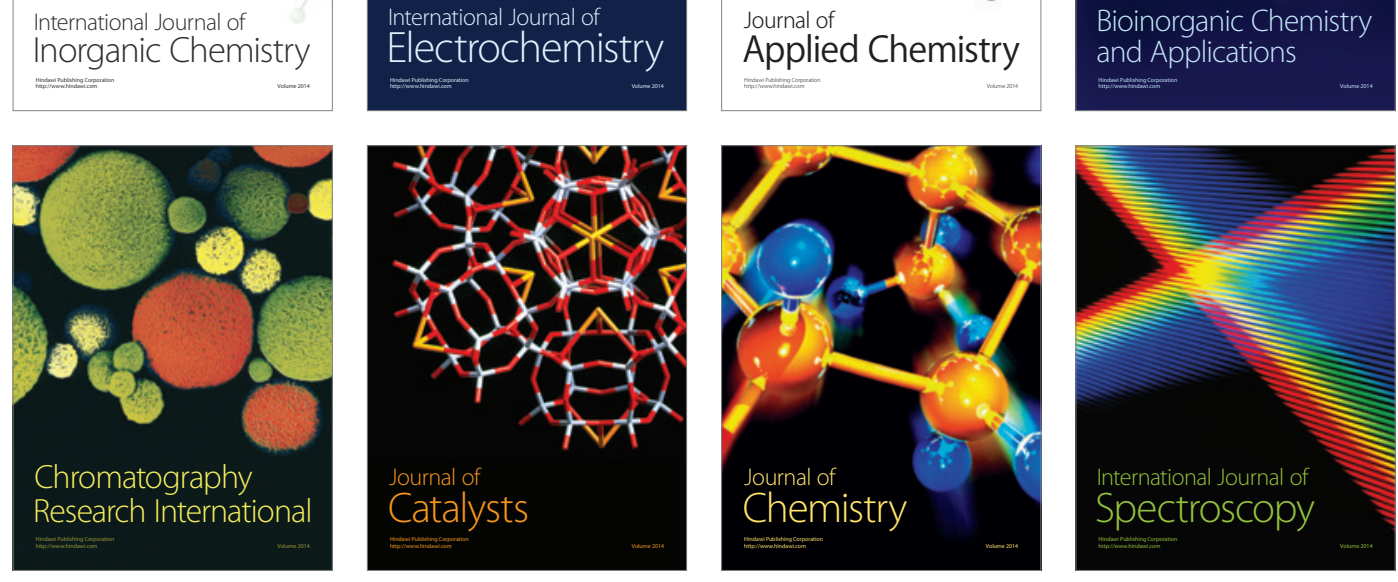